BMJ Open Diabetes Research \& Care

\section{0 years on: the impact of the discovery of insulin on clinical outcomes}

John B Buse $\left(1,{ }^{1}\right.$ Melanie J Davies, ${ }^{2}$ Brian M Frier, ${ }^{3}$ Athena Philis-Tsimikas $(1){ }^{4}$
To cite: Buse JB, Davies MJ, Frier BM, et al. 100 years on: the impact of the discovery of insulin on clinical outcomes. BMJ Open Diab Res Care 2021;9:e002373. doi:10.1136/ bmjdrc-2021-002373

Received 12 May 2021 Accepted 25 July 2021

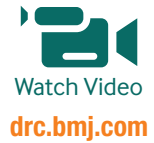

Check for updates

(C) Author(s) (or their employer(s)) 2021. Re-use permitted under CC BY-NC. No commercial re-use. See rights and permissions. Published by BMJ.

${ }^{1}$ Medicine/Endocrinology, University of North Carolina at Chapel Hill School of Medicine, Chapel Hill, North Carolina, USA ${ }^{2}$ Diabetes Research Centre, University of Leicester, Leicester, UK

${ }^{3}$ The University of Edinburgh College of Medicine and Veterinary Medicine, Edinburgh, UK

${ }^{4}$ Scripps Whittier Diabetes Institute, San Diego, California, USA

Correspondence to Dr John B Buse;

jbuse@med.unc.edu

\section{ABSTRACT}

Throughout history, up to the early part of the 20th century, diabetes has been a devastating disorder, particularly when diagnosed in childhood when it was usually fatal. Consequently, the successful pancreatic extraction of insulin in 1921 was a miraculous, life-changing advance. In this review, the truly transformative effect that insulin has had on the lives of people with type 1 diabetes and on those with type 2 diabetes who are also dependent on insulin is described, from the time of its first successful use to the present day. We have highlighted in turn how each of the many facets of improvements over the last century, from advancements in the properties of insulin and its formulations to the evolution of different methods of delivery, have led to continued improvement in clinical outcomes, through the use of illustrative stories from history and from our own clinical experiences. This review concludes with a brief look at the current challenges and where the next century of technological innovation in insulin therapy may take us.

\section{INTRODUCTION}

Insulin is a remedy primarily for the wise and not for the foolish, be they patients or doctors. Everyone knows it requires brains to live long with diabetes, but to use insulin successfully requires more brains. (Elliott $\mathrm{P}$ Joslin, 1923)

Diabetes mellitus is a chronic condition affecting 463 million people globally, ${ }^{1}$ and it is estimated that $150-200$ million people worldwide are dependent on insulin therapy for their health, although this is likely to be an underestimate. ${ }^{2}$ For people with type 2 diabetes (T2D), insulin is one of many available therapies; however, for those with type 1 diabetes (T1D), insulin therapy is vital. Nowadays, most people with T1D treated with insulin who are in good glycemic control can expect a lifespan that approaches that of the general population; ${ }^{3}$ meanwhile, in T2D, insulin is often viewed as a 'salvage treatment' or therapy of last resort. As such, it can be easy to take insulin for granted and to forget that, just over 100 years ago, the situation was very different.

It is important to recognize that the words of Elliott P Joslin above still hold true todayeven though there are many more diabetes treatment options available, using insulin optimally to achieve and maintain good glycemic outcomes from day to day while avoiding hypoglycemia, although easier for some, remains a challenge for many patients. Many people with long-standing T2D do not receive insulin in a timely manner owing to therapeutic inertia, which is highly prevalent in T2D management; indeed, the longest reported delays in treatment intensification are for insulin initiation (the median time from treatment with one (or more) oral glucose-lowering $\operatorname{drug}(\mathrm{s})$, with poor glycemic control, to treatment with insulin was 1.2-4.9 years). ${ }^{4}$ Therapeutic inertia related to insulin initiation and intensification has multifactorial origins both in patients and in clinicians, including fear of injections, treatment complexity, fear of hypoglycemia, reduced quality of life, low treatment adherence, and misperceptions concerning pain, weight gain and lifestyle interference. ${ }^{5}$

In this review, we aim to remind the reader of the truly transformative effect that insulin has had on the lives of patients from the moment of its first successful use to the present day. We highlight the various facets of improvements, including outcomes, formulations and methods of delivery, and discuss the changes and ongoing challenges in the accessibility of insulin therapy through the use of illustrative stories from history and from our own clinical practices.

\section{Diabetes: a devastating disease}

Before 1921 and that fateful, successful first preparation and administration of insulin to humans in January 1922, a diagnosis of diabetes in childhood was effectively a death sentence; many patients did not survive for more than days to weeks. There were few effective treatments beyond dietary restrictions and extended periods of bed rest. ${ }^{6}$ Patients with T1D were often kept in hospital for weeks or months at a time, while their calorie intake and glucose excretion were meticulously recorded. ${ }^{8}$ The majority of physicians relied either on starvation treatments 
A

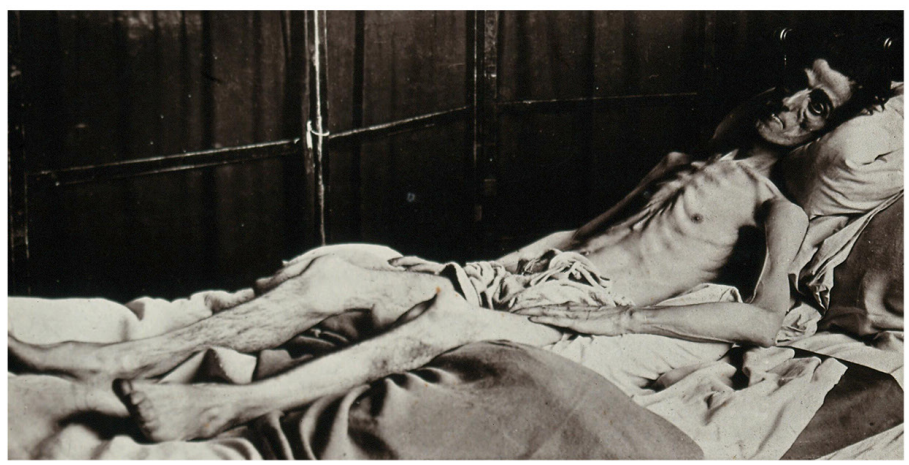

B

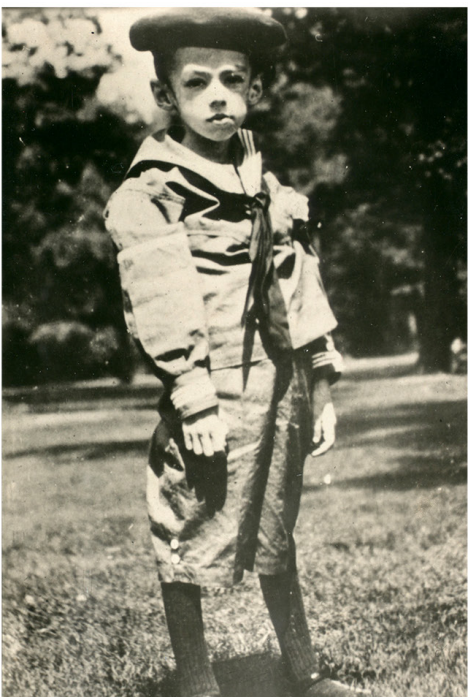

Figure 1 The reality of the treatment of diabetes before insulin. (A) Photograph of a man with diabetes and emaciation before treatment with insulin, ca. 1925. Reproduced with permission from Understanding Animal Research (B) Photograph of Teddy Ryder prior to starting insulin treatment, July 10, 1922. Reproduced with permission from the University of Toronto.

that combined low-calorie diets with periods of fasting, as promoted by Allen and Joslin, or low-carbohydrate, ketogenic diets to treat children with diabetes (figure 1). ${ }^{67}$ The aim of the severe calorie restriction was to reduce glycosuria, dehydration and the development of diabetic ketoacidosis, which was a frequent cause of death in children with diabetes. However, the extent of the calorie restriction had to be carefully monitored owing to the negative effect on growth and the ability of the patient to resist and respond to infections. The regimen was unpleasant and difficult to maintain, especially once patients were no longer under specialist supervision. ${ }^{7}$ In contrast to the bleak prospective outcomes in pediatric patients, it was observed that adults who presented with diabetes could not only benefit from calorie restriction, but were far less prone to experience the devastating outcomes that affected children (the difference between T1D and T2D was not understood at that time).

\section{Insulin: a life-saving discovery}

The discovery and successful extraction of insulin by Frederick Banting, Charles Best, John Macleod and James Collip, which has been extensively reviewed, including a comprehensive account by the Canadian historian Michael Bliss, was literally life-saving and was described as one of the miracles of modern medicine. ${ }^{6}$ Insulin therapy was the first treatment that helped patients return to a healthy weight and to restore their levels of energy, while reversing and preventing diabetic ketoacidosis. Moreover, the decision of the researchers to license insulin for just one Canadian dollar and to make it freely available worldwide enabled many companies to begin extracting and purifying insulin, speeding up supply to those most in need. ${ }^{9}$

The first administration of insulin in the USA took place in May 1922 to James Dexter Havens, then aged
22 years, in Rochester, New York. This came about in a slightly unusual way. James' father was an executive at Eastman Kodak; after hearing about a potential experimental treatment for diabetes that was being developed in Canada, he contacted George Snowball, the manager of a Kodak store in Toronto, Ontario, to see if he could obtain any further information. George Snowball asked his golfing partner, who was none other than John Macleod! Following the announcement that the treatment of Leonard Thompson had been successful, a shipment of insulin to Rochester was arranged and the first injection outside Canada was administered on May 22, 1922. After the initial administration of three injections of insulin proved a failure at lowering James' hyperglycemia, his father and physician persuaded Frederick Banting to travel to Rochester to oversee the treatment in person. Despite various setbacks, which included James experiencing reactions to impurities in the preparations and having a severe allergic reaction to porcine insulin, thanks to the treatment, he lived to father two children and became an acclaimed woodcut and graphic artist, dying from complications of colon cancer at the age of 60 years. His works can be found in many Fine Art institutions, including the Metropolitan Museum of Art and the Brooklyn Museum in New York City, New York, USA, and the Library of Congress in Washington, DC, USA. ${ }^{10}$ Similarly, just 10 days after James Dexter Havens started insulin treatment, William Sansum in California successfully treated his first American patient, Charles E Cowan, who was 51 years old and, remarkably, lived for another 39 years without developing a single complication. ${ }^{11}$

The first administration of insulin to a patient in Europe took place in Edinburgh, Scotland, at a similar time to the first administration of insulin by Elliott $\mathrm{P}$ Joslin in Boston, Massachusetts, USA, in August 1922. 


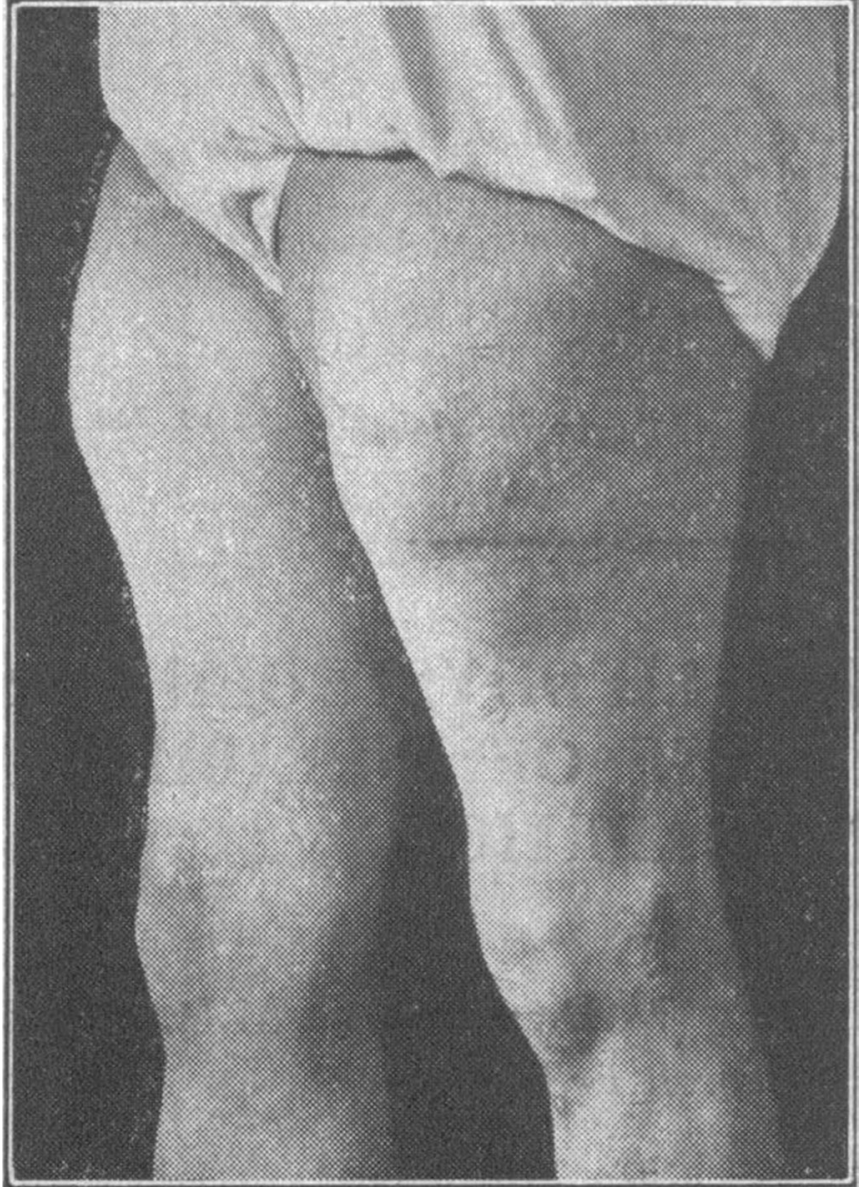

Figure 2 Patient with lipodystrophy. Reproduced with permission from Paley and Scott. ${ }^{18}$

Given the impossibility of transporting the early (and initially very limited) supplies of insulin from Canada to Europe, the Edinburgh physicians had to make their own supply of insulin locally by following very detailed instructions provided by John Macleod. Their first extraction was so potent that rabbits in which it was tested died from profound hypoglycemia, but, through dilution and further experimentation, a successful preparation was achieved. ${ }^{12}$ The first patient they treated was Norman Purves Walker, a 60-year-old physician in the dermatology department, who was subsequently knighted when he became president of the General Medicine Council in 1923. He appears to have had a form of late-onset T1D. Before treatment with insulin, he had become so weak that he had to be carried to lecture theaters and remain seated while instructing his students; treatment with insulin restored his vigor and he lived until $1942 .^{12}$ Spain and Denmark also recorded their first treatments of patients with insulin shortly after the team in Edinburgh. ${ }^{11}$

Despite the publication of a paper by Elliott P Joslin in June 1923 (reassuringly entitled 'The routine treatment of diabetes with insulin'), ${ }^{13}$ in which he already established many core principles, including subcutaneous injection, administration before meals, regular testing of urine glucose before and after meals (blood glucose measurement was difficult and inaccurate before the development of the autoanalyser in the 1940s) and a belief that patients could be educated to self-administer insulin, it is important to note that there were many differing opinions and that in many countries the introduction of insulin was not straightforward. It raised new challenges for physicians who were treating patients with T1D, including the potential for hypoglycemia, the requirement for administration by injection and the complexity of adjusting the dose according to food intake and amount of exercise, which some physicians thought was too complex for patients to be expected to handle themselves without supervision. ${ }^{14}$ Fears surrounding the challenges of patients self-managing treatment and concerns regarding their ability to do so meant that, initially, insulin was not the liberating treatment it could have been. To mitigate concerns, many patients were initially treated with small doses to prevent hypoglycemia and to produce an average weight gain of $1 \mathrm{lb}$ in 15 days. ${ }^{6}$ Outside of the main teaching hospitals, the lack of experience meant that care could often be quite variable from patient to patient and that patient education was often not provided in a consistent manner. ${ }^{15}$ Many physicians were initially skeptical that insulin could or should be administered by patients. Moreover, insulin was purified from porcine or bovine pancreatic extracts so, because the initial yield per pancreas was quite low, the supply was dependent on obtaining sufficient supplies of pancreases and large quantities of alcohol suitable for the extraction process. In many countries, this also influenced the initial price of insulin because supply struggled to meet demand. In the UK at that time, there was an embargo on the import of Canadian cattle, which greatly reduced the availability of fresh, raw pancreases. A further challenge was the cost of alcohol used in the extraction process; until the UK Customs and Excise government department granted an exemption from duty to specially denatured alcohol, the cost was prohibitive and meant that initial treatment with insulin was predominantly the preserve of the wealthy. However, manufacturing capacity was eventually successfully increased, allowing the first supplies of British-made insulin to reach UK hospitals in April 1923. ${ }^{14}$

As recognized by Joslin in his seminal publication in 1923, treatment with extracted insulin was labourintensive; the short duration of action of regular (soluble) insulin meant that several subcutaneous injections might be required each day, ${ }^{13}$ and careful dose adjustments might be needed based on meticulous monitoring of carbohydrate intake and exercise. As the number of patients under their care grew, the team in Edinburgh realized that the restrictive starvation diet that was used until the advent of insulin was no longer sufficient and that tailoring carbohydrate intake to each individual was proving to be far too time-consuming. They therefore developed a set of standardized diet plans that could be applied to the different stages of treatment. ${ }^{12}$ Another 
challenge was that not all patients responded to treatment with insulin as expected; a subset of those with T1D experienced repeated periods of hypoglycemia and hyperglycemia without any obvious cause, a condition that was described as 'brittle diabetes' by Woodyatt in the 1930s. ${ }^{16}$ However, physicians learned quickly from their early experiences and by 1926, many of the principles that still guide treatment today had been formulated. These included the following recommendations from the UK Medical Research Council: injections should be administered at least once a day using a fine needle; hypoglycemia can be reversed by giving glucose but should be avoided altogether by timing insulin administration in relation to food, with meals being followed by an injection of insulin within approximately $15 \mathrm{~min}$; blood sugar should be checked frequently to prevent glycosuria; and insulin doses should be individually determined. ${ }^{14}$ At this point, the continuation of restrictive diets was encouraged and there was little mention of injection site rotation. However, in his book published in 1928, Joslin referred to the differences seen in response depending on the location of the injection site and the importance of varying the site of injection. ${ }^{17}$

\section{The path of insulin progress}

The short duration of action meant that patients were having to administer painful injections several times a day. Moreover, the early preparations of insulin extracted from either porcine or bovine pancreases were relatively impure, resulting in patients experiencing problems such as lipodystrophy, allergic reactions at injection sites and antibody-mediated insulin resistance. ${ }^{18-20}$ Lipodystrophy could take the form of either lipoatrophy, which was common, occurring in $33 \%-55 \%$ of patients, or lipohypertrophy, which was much rarer, occurring in $3 \%-7 \%$ of patients (figure 2 ). It was postulated by Lamar that the presence of lipohypertrophy may explain some cases of brittle diabetes through the sporadic release of insulin from fat deposits leading to unexpected hypoglycemia. ${ }^{18}$ The manifestation of allergic reactions could range from localized itchiness, soreness or a burning sensation at the site of injection to a generalized reaction of urticaria, edema or pruritus, which could also be accompanied by the presence of gastrointestinal or respiratory difficulties; in rare cases, anaphylaxis occurred. ${ }^{19}$ Local reactions were seen in up to $56 \%$ of patients, ${ }^{21}$ but they were often only a temporary inconvenience. In contrast, generalized reactions were more debilitating for patients and required physicians to consider either complete cessation of insulin treatment or a process of desensitization. ${ }^{19}$ Consequently, much attention in the early period was focused on both improving the purity of the preparation and extending the duration of action. ${ }^{22}$ Extending the duration of action through the addition of zinc and protamine to the formulation was of great benefit for patients because it reduced the number of injections required to just two each day. However, the day-to-day glucose-lowering effect remained highly variable, ${ }^{23}$ meaning that patients still had to monitor their urinary glucose levels and carbohydrate intake carefully and that hypoglycemia remained a substantial risk.

The discovery of the amino acid sequence of insulin by Fred Sanger in 1960 was another advance that improved the care of patients, by enabling human insulin to be manufactured for the first time. ${ }^{24}$ It was not until recombinant technology was developed in the 1970s, however, that human insulin preparations became more widely available. At about the same time as the human insulin amino acid sequence was elucidated, it was also becoming clear to many clinicians that, although the advent of insulin had enabled children with diabetes to grow and to develop normally, their average lifespan was still only two-thirds that of their peers owing to the development of microvascular and macrovascular complications. ${ }^{25} \mathrm{It}$ was suggested that some of this could be attributed to a lack of education of patients and their families and also, perhaps, to a degree of laxity on the part of physicians regarding the need to achieve good glycemic control. The need for strict glycemic control was itself a point that was debated well into the second half of the 20th century, with a number of prominent diabetologists arguing that intensive therapy and strict glycemic control were unnecessary and potentially dangerous. For several decades, many specialists followed a laissez-faire approach to treatment, allowing chronic hyperglycemia that resulted in many patients developing devastating microvascular and macrovascular complications. ${ }^{26-28}$ This debate was finally laid to rest by the results of the landmark Diabetes Control and Complications Trial/Epidemiology of Diabetes Interventions and Complications Study, ${ }^{29}{ }^{30}$ although it still took several years for the recommendations from this pivotal trial to achieve broad adoption.

In addition, by the $1950 \mathrm{~s}-1960 \mathrm{~s}$, the fundamental differences with regard to residual $\beta$-cell function between 'juvenile diabetes' (T1D) and 'maturity-onset diabetes' (T2D) were becoming more clearly understood. For adults with T2D, prior to the use of sulphonylureas in the 1940s and biguanides in the 1950s, insulin was the only medication available for treatment. Data from the early trials of sulphonylureas demonstrated a clear difference in efficacy between these two populations, ${ }^{25}$ indicating that they required different treatments and types of care. Separate approaches to the management of T1D and T2D began to develop. However, even after the practice of initially using oral agents to treat T2D became established, insulin was still required for optimal management once a state of insulin deficiency was reached. From the 1970s onwards, there was an explosion in the understanding and development of new insulin treatments for patients with diabetes. Importantly, advances in purification processes, including the use of gel filtration, resulted in the production of highly purified preparations, which successfully reduced the immunogenicity of previous preparations, so diminishing the adverse outcomes experienced by patients. ${ }^{31-33}$ 
Box 1 Personal recollection of the effects of the

limitations of neutral protamine Hagedorn (NPH) insulin

'I still remember vividly how we took care of VA [Veterans Affairs] patients on the metabolic ward 25 years ago, making rounds with our attendings and trainees. We would ask the vets to prick their finger with a fat lancet and drop the blood on a strip, wait, wait, and then match it to the right colour to measure their glucose level. Then send them for a walk around the wards, eat lunch and then have them check again to get a postprandial glucose value. They needed lunch so they wouldn't get hypoglycaemia from the NPH insulin that they had received that morning ...' (Athena Philis-Tsimikas)

Purified and monocomponent preparations reduced the occurrence of allergic reactions but did not prevent them. ${ }^{21}$ Irrespective of the level of purity, the fact remained that animal-based insulin preparations produced glycemic profiles that were far from physiological. In addition, during pregnancy, anti-insulin antibodies were able to cross the placenta, which could pose a danger to the fetus. ${ }^{31}$ Lipohypertrophy, which still developed with the use of purified insulins, was shown to affect the rate of insulin absorption, with potential consequences for patients in terms of frequent and unpredictable hyperglycemic or hypoglycemic episodes. ${ }^{34}$

The development of human insulin, either through amino acid substitutions or through the use of recombinant DNA techniques, provided an alternative that further reduced the immunogenicity associated with earlier animal insulin preparations. ${ }^{32} 35$ Importantly, the switch to human insulin preparations, including premixed insulins, was able to reverse the abnormal complement activation that occurred in response to porcine insulin preparations in children with T1D. ${ }^{36}$ However, human neutral protamine Hagedorn (NPH) insulin, or isophane insulin, was still prone to intraindividual and interindividual variability, which required careful monitoring to ensure that hypoglycemia was avoided (box 1).

Most excitingly, recombinant DNA technology not only allowed human insulin to be manufactured at scale but also enabled, for the first time, the properties of the insulin molecule to be manipulated through selected amino acid changes to promote desirable features. This allowed the creation of short-acting and long-acting insulin analogs. ${ }^{37}$ The aim of such manipulation was to facilitate the creation of regimens that more accurately mimicked the physiological profile of insulin release: a low constant background level, with brisk spikes in concentration in response to the rise in plasma glucose following meals. ${ }^{37}$

The development of the long-acting insulin analogs, insulin glargine and insulin detemir provided patients with a low level of insulin activity throughout the day with just one or two injections. Given that the day-to-day variability with these long-acting analogs was lower than with NPH insulin, the risk of hypoglycemia was also reduced. ${ }^{38}$ This advance also heralded the advent of the treat-to-target approach, making patients' self-titration of basal insulin more accessible. Despite hypoglycemia being the principal barrier to maintaining strict glycemic control, a meta-analysis of patients' quality of life studies failed to identify a significant difference in quality of life measurements between NPH insulin and insulin glargine U100. ${ }^{40}$ A single study for insulin detemir did show an improvement in quality of life following treatment initiation. ${ }^{41}$ Recently, the development of insulin degludec and insulin glargine U300 has further lowered the risk of hypoglycemia and glucose variability compared with $\mathrm{NPH}$ insulin, and also compared with insulin detemir or insulin glargine U100, leading to improved quality of life outcomes. ${ }^{42-45}$ This reduced risk of hypoglycemia allows patients to have much more flexibility when selecting the types of food to eat and the timing of meals, enabling them to make decisions that better suit their lifestyles. Interestingly, one development that has occurred recently as a consequence is the increasing interest in ketogenicstyle diets, comprising high protein and fat content with minimal carbohydrates, coming almost full circle from the early days of diabetes management. The availability of new rapid-acting insulins means that people with diabetes can adjust their insulin doses to match variations in carbohydrate intake on a day-by-day basis, from consuming almost no carbohydrates in some meals to eating others containing a high sugar and fat content, such as a burger and French fries, without disrupting their control. As such, patients are able to go about their lives and undertake all their desired activities, from participating in sports to eating out with friends, while being confident in the knowledge that they are in control of their diabetes, rather than it being in control of them. Recently, the first once-weekly basal insulin, insulin icodec, has completed a pivotal phase 2 clinical trial, in which it has demonstrated effective glycemic control without increased risk of clinically relevant hypoglycemia ${ }^{46}$; other approaches in the pipeline are expected to report results soon.

At the other end of the action-profile spectrum, rapidacting insulin analogs have provided a cleaner actionprofile peak than previous preparations. Modifications to improve time of onset have allowed people to take their insulin closer to the ingestion of food, thereby making it easier to balance dose requirements with carbohydrate consumption. ${ }^{47}$ For people with T2D, an all-analog basal-bolus regimen provided greater control with lower risk of hypoglycemia than an all-human insulin-based regimen. ${ }^{48} 49$

\section{Advances in delivery methods}

To focus on insulin alone is to leave out a crucial aspect of treatment for the patient-the method of its delivery. Keeping pace with the development of insulin, the methods of delivery have also improved over time (box 2). The first glass syringes, produced by Becton Dickinson, were heavy and breakable with long, largebore needles that needed to be sterilized by boiling before each reuse. The first disposable syringes were 
Box 2 Personal recollection of the effect of diabetes management on patient's lives

'I remember in Sheffield, England in the 1980's where I was working as a junior 'house' doctor during the first subcutaneous pump trials in the UK; the pumps were large and very unwieldy. Peritoneal delivery of insulin was also being trialled and I vividly remember a young woman in her early 20s who had had type 1 diabetes since a teenager who was regularly admitted to our diabetes specialist ward. On this occasion she had been admitted with peritonitis following a failed trial of the peritoneal insulin delivery system. The reason she had been included in the trial was because of repeated admissions with ketoacidosis and overall 'poor' glycaemic control. I remember sitting by her bed while she was on the ward listening to her complete frustration and 'burn out' with diabetes and I felt just as frustrated because of the lack of both psychological and technical support that we had available back then to offer. How amazing the transformation has been over recent decades, completely transforming what we are able now to offer people living with type 1 diabetes.' (Melanie Davies)

also made of glass in 1954, closely followed by plastic syringes in $1955 .^{50}$ These came with either an integrated or a disposable needle and reduced the pain of injection compared with previous iterations; however, they were still prone to cause problems of inaccurate dosing owing to the design. The development of specific U100 plastic insulin syringes with units marked down the side of the syringe helped to reduce this risk, and they could be safely reused. Other advances came with the progressive development of shorter, smaller bore needles to minimize injection pain for patients, but issues around inaccuracy of dosing remained. ${ }^{50} \mathrm{~A}$ major advance in insulin delivery was the development of the first insulin pen device in the $1980 \mathrm{~s} .{ }^{51}$ These devices provide a simple dial system to allow the setting of the required dose, and have been shown to be more accurate than vials and syringes. ${ }^{52}$ Moreover, by containing insulin in a prefilled cartridge, the complexity of administering each dose is reduced, removing the need for resuspension or for ensuring that there is no air in the syringe before administration. They are also easy and convenient to carry. Unsurprisingly, patients have consistently shown a preference for pen devices over vials and syringes. ${ }^{53} 54$ Pen devices have continued to evolve in design, including the use of color to make them more attractive to children, modifications that reduce the degree of force needed to deliver the dose, and improvements in the dose display. ${ }^{50}$

The measurement of plasma glucose has also, thankfully, moved on in recent years from the reliance on observing a color change on paper strips, requiring a painful finger stick with a lancet to obtain a drop of blood for each test. Now, flash glucose monitoring and continuous glucose monitoring (CGM) devices that provide a steady stream of data on interstitial tissue glucose levels are available, allowing the individual to take action in real time in response to a fall or a rise in their values. ${ }^{50}$ These have also provided clinicians with access to a wealth of data around how long an individual is spending in the target range of good glycemic control throughout each 24-hour period, known as 'percentage time in glycemic range'. Perhaps one of the most interesting recent developments has been that of connected or smart insulin pens, whereby data can be uploaded from the pen to track exactly when doses are given and the size of each dose. When combined with CGM technology, people with diabetes and clinicians can now see the relationship between the insulin dose and the effect on glucose levels in real time, providing a new level of insight into how the management of each individual's diabetes might be optimized.

Another major advance has been the evolution of continuous subcutaneous infusion devices. From the development of the first device in the 1970s, their use has become much greater in the past 20 years. ${ }^{55}$ Pumps deliver a continuous low-level infusion of rapid-acting insulin analog to mimic the basal level that occurs endogenously. Rapid spikes in the infusion can be triggered in response to meals; in the first iterations, this was done manually by the patient setting the required dose. ${ }^{55}$ The combination of insulin pumps with CGM technology has led to the automation of insulin delivery, based on the CGM data being received. Insulin suspension technology to prevent hypoglycemia is an additional safety feature that was added to many pump devices; it stops insulin infusion if a fall in glucose indicates a risk of developing hypoglycemia, which can be predicted from CGM data. ${ }^{55}$ For many patients, insulin pumps have provided greater flexibility in terms of lifestyle and meals than other insulin delivery methods, improving their quality of life. ${ }^{567}$ However, there are disadvantages in terms of the visibility and bulkiness of the pumps, and some physical restrictions were reported negatively. ${ }^{58}$

So far, the narrative has focused on the positive developments for patients in terms of improving outcomes and reducing the daily burden imposed by treatment requirements (figure 3 ), but the reality may not be so rosy. Despite the noble intentions of the team who discovered insulin and gifted it to the world, the current cost of insulin is now prohibitive for many people with diabetes worldwide. ${ }^{59}$ In 2016, a survey of 13 countries found that the median availability of human insulins was higher than that of analog insulins ( $55 \%-80 \%$ compared with $55 \%-63 \%) .{ }^{59}$ The Lancet Commission on diabetes reported that access to insulin remains an issue in both high-income and low-income countries, although the underlying reasons differ. ${ }^{60}$ Patients who struggle with access may have to resort to donating, trading, borrowing and purchasing diabetes medications and supplies. ${ }^{59} 61$ It is an issue of deep concern that 100 years after the discovery of this life-saving medicine, it is still not accessible worldwide to many of those in need.

\section{Looking to the next 100 years}

Despite the serious nature of the remaining challenges, future developments offer much hope. With regard to challenges of accessibility, several programs are aiming 


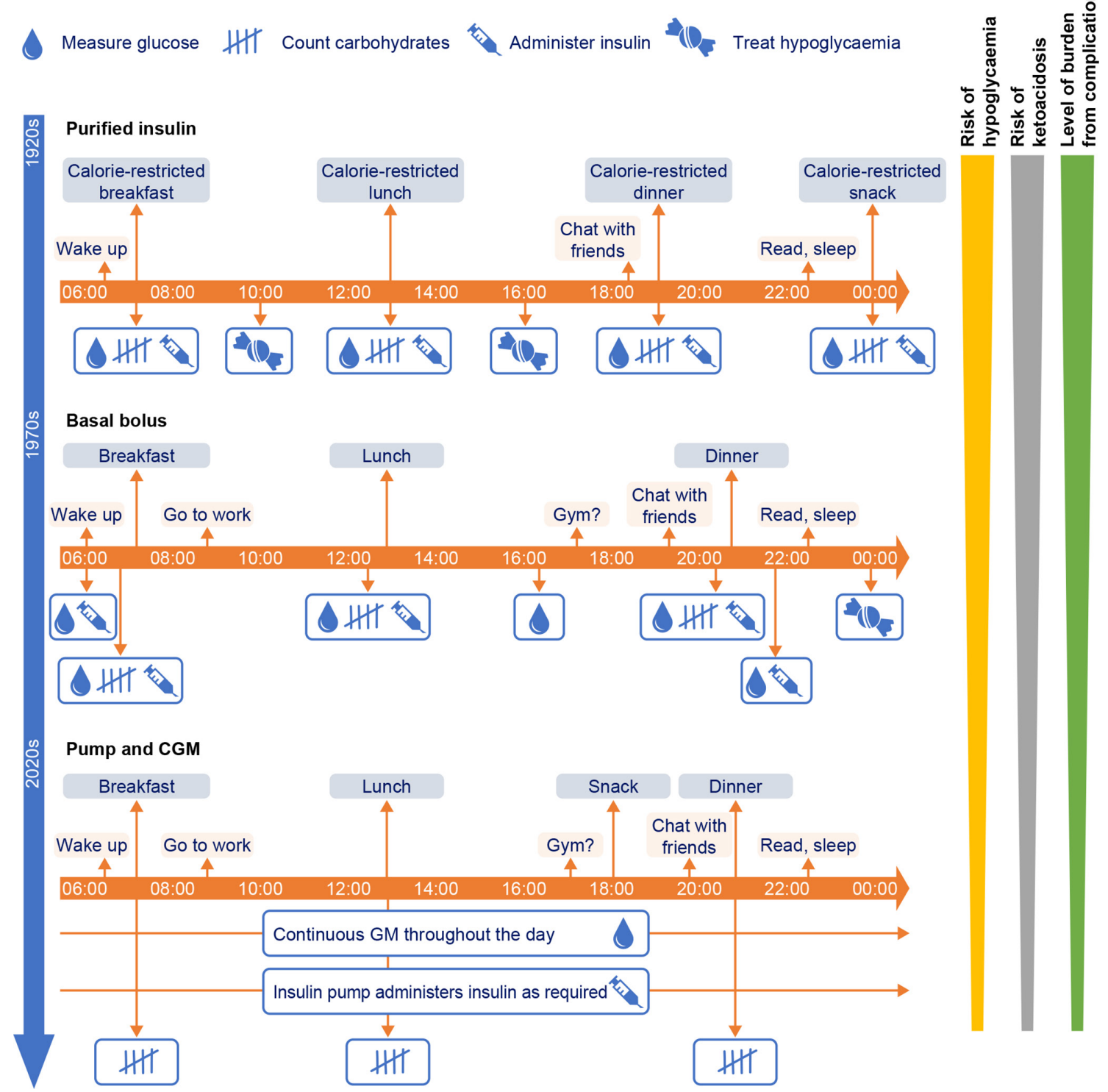

Figure 3 Example changes in the burden of type 1 diabetes treatment over the past 100 years. GM, glucose monitoring.

to improve access to insulin treatment, particularly in developing nations. In addition, research continues into alternative formulations of insulin, including heatstable formulations that can be more easily transported and stored for long periods without the need for refrigeration, and glucose-sensitive formulations for injection. $^{62}{ }^{63}$ Although no oral insulin compound has yet been successful, this is another area in which research is ongoing. ${ }^{63} 64$ Treatment options available to clinicians and patients will continue to improve, with technology enabling the development of smarter devices, including pumps that are more physiologically responsive and discreet. ${ }^{50}$ Perhaps furthest off, but most exciting of all, are the gene therapy and stem cell therapeutic approaches for T1D that are also under investigation; they offer the hope that, in the next century, there may finally be a cure that can be offered to people with diabetes, rather than the prospect of lifelong insulin replacement regimens. ${ }^{6566}$
In conclusion, the 100 years since the discovery of insulin have seen the lives of many people transformed. The present goal is to make sure that every single individual who needs insulin is able to access and benefit from it; only then will we be able to say that the aspirations of those whose remarkable discovery started us on this path have truly been achieved.

Correction notice This article has been corrected since it was published. Orcid Id of Dr Athena Philis-Tsimikas has been added.

Acknowledgements In addition to the primary affiliations provided, MJD is also affiliated to University Hospitals of Leicester NHS Trust, Leicester, UK, and is co-funded by the National Institute of Health Research (NIHR) Leicester Biomedical Research Centre, Leicester, UK. AP-T is also affiliated with the Scripps Research Translational Institute, San Diego, California, USA.

Contributors All authors contributed equally to the concept, data acquisition and interpretation, and manuscript drafting process. All authors provided approval of the final version for submission.

Funding Novo Nordisk funded editorial support from Gemma Rogers, Oxford PharmaGenesis, 0xford, UK, comprising text and reference formatting support and 
copyright research for figures. Novo Nordisk was also provided with the opportunity to perform a medical accuracy review.

Competing interests JBB's contracted consulting fees and travel support for contracted activities are paid to the University of North Carolina by Adocia, AstraZeneca, Eli Lilly, Fractyl, Intarcia Therapeutics, Lexicon, MannKind, Metavention, Novo Nordisk, Sanofi, Senseonics, vTv Therapeutics and Zafgen; he reports grant support from AstraZeneca, Eli Lilly, Intarcia Therapeutics, Johnson \& Johnson, Lexicon, NovaTarg, Novo Nordisk, Sanofi, Theracos, Tolerion and vTv Therapeutics; he has received fees for consultation from Cirius Therapeutics, Eli Lilly, Fortress Biotech, Moderna, Pendulum Therapeutics and Zealand Pharma; he holds stock/options in Mellitus Health, Pendulum Therapeutics, PhaseBio, Praetego and Stability Health; and he is supported by grants from the National Institutes of Health, Patient Centered Research Institute, Juvenile Diabetes Research Foundation International and the American Diabetes Association. JBB is a member of the editorial board for BMJ Open Diabetes Research \& Care. MJD has acted as consultant, advisory board member and speaker for Boehringer Ingelheim, Lilly, Novo Nordisk and Sanofi; an advisory board member and speaker for AstraZeneca; an advisory board member for Gilead Sciences, Janssen, Lexicon and Servier; and as a speaker for Mitsubishi Tanabe Pharma Corporation, Napp Pharmaceuticals and Takeda Pharmaceuticals International. She has received grants in support of investigator and investigator-initiated trials from AstraZeneca, Boehringer Ingelheim, Janssen, Lilly, Novo Nordisk and Sanofi-Aventis. BMF has served on advisory boards for Eli Lilly and Zucara Therapeutics, and has given lectures for Abbott, Eli Lilly, MSD, Novo Nordisk, Roche and Sanofi. AP-T conducts research and serves on advisory boards for Abbott, Dexcom, Eli Lilly, Novo Nordisk and Sanofi. Compensation is provided to her employer Scripps Health, and no direct or indirect funds are transferred to the author.

Patient consent for publication Not required.

Provenance and peer review Not commissioned; externally peer reviewed.

Data availability statement № data are available.

Open access This is an open access article distributed in accordance with the Creative Commons Attribution Non Commercial (CC BY-NC 4.0) license, which permits others to distribute, remix, adapt, build upon this work non-commercially, and license their derivative works on different terms, provided the original work is properly cited, appropriate credit is given, any changes made indicated, and the use is non-commercial. See: http://creativecommons.org/licenses/by-nc/4.0/.

ORCID IDs

John B Buse http://orcid.org/0000-0002-9723-3876

Athena Philis-Tsimikas http://orcid.org/0000-0002-3986-9630

\section{REFERENCES}

1 International Diabetes Federation. Diabetes atlas. 9th edn. Brussels, Belgium: International Diabetes Federation, 2019.

2 Garg SK, Rewers AH, Akturk HK. Ever-increasing insulin-requiring patients globally. Diabetes Technol Ther 2018;20:1-4.

3 Heald AH, Stedman M, Davies M, et al. Estimating life years lost to diabetes: outcomes from analysis of national diabetes audit and office of national statistics data. Cardiovasc Endocrinol Metab 2020;9:183-5

4 Khunti K, Gomes MB, Pocock S, et al. Therapeutic inertia in the treatment of hyperglycaemia in patients with type 2 diabetes: a systematic review. Diabetes Obes Metab 2018;20:427-37.

5 Escalada J, Orozco-Beltran D, Morillas C, et al. Attitudes towards insulin initiation in type 2 diabetes patients among healthcare providers: a survey research. Diabetes Res Clin Pract 2016;122:46-53.

6 de Leiva-Hidalgo A, de Leiva-Pérez A. Experiences of first insulintreated patients (1922-1923). Am J Ther 2020;27:e13-23.

7 Mazur A. Why were "starvation diets" promoted for diabetes in the pre-insulin period? Nutr $J$ 2011;10:23

8 Bliss M. The history of insulin. Diabetes Care 1993;16 Suppl 3:4-7.

9 Rutty CJ. "Couldn't live without it": diabetes, the costs of innovation and the price of insulin in Canada, 1922-1984. Can Bull Med Hist 2008:25:407-31.

10 Madeb R, Koniaris LG, Schwartz SI. The discovery of insulin: the rochester, new york, connection. Ann Intern Med 2005;143:907-12.

11 de Leiva-Hidalgo $A$, de Leiva-Pérez $A$, Bruguès-Bruguès $E$. From pancreatic extracts to artificial pancreas: history, science and controversies about the discovery of the pancreatic antidiabetic hormone. Avances en Diabetología 2011;27:15-26.
12 Lyon RL. The early days of insulin use in edinburgh. BMJ 1990;301:1452-4.

13 Joslin EP. The routine treatment of diabetes with insulin. JAMA 1923;80:1581-3.

14 Tattersall RB. A force of magical activity: the introduction of insulin treatment in britain 1922-1926. Diabet Med 1995;12:739-55.

15 McEwen $\mathrm{H}$, McNeil DL, Thorson SB, et al. Experience with a diabetic service in an "open" hospital. Can Med Assoc J 1963;89:1133-7.

16 Amiel SA. "Brittle" diabetes. BMJ 1991;303:260-1.

17 Joslin EP. The treatment of diabetes mellitus. Philadelphia, USA: Lea and Febiger, 1928.

18 Paley RG, Scott MH. Severe insulin lipodystrophy as a possible cause of instability in diabetics. Br Med $J$ 1958;2:1331-4.

19 Watson EM. Non-hypoglycaemic (allergic) insulin reactions. Can Med Assoc J 1942; 47:336-9.

20 Lowell FC. Immunologic studies in insulin resistance I. Report of a case exhibiting variations in resistance and allergy to insulin. J Clin Invest 1944;23:225-31.

21 Simmonds JP, Russell GI, Cowley AJ, et al. Generalised allergy to porcine and bovine monocomponent insulins. Br Med $J$ 1980;281:355-6.

22 Shah VN, Moser EG, Blau A, et al. The future of basal insulin. Diabetes Technol Ther 2013;15:727-32.

23 Lauritzen T, Pramming S, Gale EA, et al. Absorption of isophane (NPH) insulin and its clinical implications. $\mathrm{Br} \mathrm{Med} \mathrm{J}$ 1982;285:159-62.

24 Sanger F. Chemistry of insulin. Br Med Bull 1960;16:183-8.

25 Belmonte MM. The future of the diabetic child. Can Med Assoc J 1963;88:1112-6.

26 Walker GF. Reflections on diabetes mellitus; answers to a questionnaire. Lancet 1953;265:1329-32.

27 Tchobroutsky G. Relation of diabetic control to development of microvascular complications. Diabetologia 1978:15:143-52.

28 Wolff SP. Is hyperglycemia risky enough to justify the increased risk of hypoglycemia linked with tight diabetes control? Biochem Med Metab Biol 1991:46:129-39.

29 Diabetes Control and Complications Trial Research Group, Nathan DM, Genuth S, et al. The effect of intensive treatment of diabetes on the development and progression of long-term complications in insulin-dependent diabetes mellitus. N Engl J Med 1993;329:977-86.

30 Nathan DM, Group DER, DCCT/EDIC Research Group. The diabetes control and complications trial/epidemiology of diabetes interventions and complications study at 30 years: overview. Diabetes Care 2014:37:9-16.

31 Home PD, Alberti KG. The new insulins. their characteristics and clinical indications. Drugs 1982;24:401-13.

32 Wilson RM, Douglas CA, Tattersall RB, et al. Immunogenicity of highly purified bovine insulin: a comparison with conventional bovine and highly purified human insulins. Diabetologia 1985;28:667-70.

33 Home PD, Mann NP, Hutchison AS, et al. A fifteen-month doubleblind cross-over study of the efficacy and antigenicity of human and pork insulins. Diabet Med 1984;1:93-8.

34 Young RJ, Hannan WJ, Frier BM, et al. Diabetic lipohypertrophy delays insulin absorption. Diabetes Care 1984;7:479-80.

35 Dorchy H, Duchateau J, Bosson D, et al. Transfer from purified porcine insulins to semisynthetic human insulins decreases insulin antibodies and circulating immune complexes in diabetic children and adolescents. A two-year follow-up. Diabete Metab 1989:15:107-10.

36 Duchateau J, Schreyen H, Dorchy H. Intermediate and long-acting insulin preparations without protamine sulphate are complement activators in vitro. Diabete Metab 1992;18:272-6.

37 Heise T, Heinemann L. Rapid and long-acting analogues as an approach to improve insulin therapy: an evidence-based medicine assessment. Curr Pharm Des 2001;7:1303-25.

38 Heise T, Nosek L, Rønn BB, et al. Lower within-subject variability of insulin detemir in comparison to NPH insulin and insulin glargine in people with type 1 diabetes. Diabetes 2004;53:1614-20.

39 Rys $\mathrm{P}$, Wojciechowski P, Rogoz-Sitek A, et al. Systematic review and meta-analysis of randomized clinical trials comparing efficacy and safety outcomes of insulin glargine with NPH insulin, premixed insulin preparations or with insulin detemir in type 2 diabetes mellitus. Acta Diabetol 2015;52:649-62.

40 Almeida PHRF, Silva TBC, de Assis Acurcio F, et al. Quality of life of patients with type 1 diabetes mellitus using insulin analog glargine compared with NPH insulin: a systematic review and policy implications. Patient 2018:11:377-89.

41 Liebl A, Andersen H, Svendsen AL, et al. Resource utilisation and quality of life following initiation of insulin detemir in patients with type 2 diabetes mellitus. Int J Clin Pract 2013;67:740-9. 
42 Owens DR, S Bailey T, Fanelli CG, et al. Clinical relevance of pharmacokinetic and pharmacodynamic profiles of insulin degludec $(100,200 \mathrm{U} / \mathrm{mL})$ and insulin glargine $(100,300 \mathrm{U} / \mathrm{mL})-a$ review of evidence and clinical interpretation. Diabetes Metab 2019;45:330-40.

43 Weatherall J, Polonsky WH, Lanar S, et al. When insulin degludec enhances quality of life in patients with type 2 diabetes: a qualitative investigation. Health Qual Life Outcomes 2018;16:87.

44 Lecumberri E, Ortega M, Iturregui M, et al. Quality-of-life and treatment satisfaction in actual clinical practice of patients with type 1 diabetes mellitus (T1DM) and hypoglycemia treated with insulin degludec. Curr Med Res Opin 2018;34:1053-9.

45 Philis-Tsimikas A, Klonoff DC, Khunti K, et al. Risk of hypoglycaemia with insulin degludec versus insulin glargine U300 in insulin-treated patients with type 2 diabetes: the randomised, head-to-head CONCLUDE trial. Diabetologia 2020;63:698-710.

46 Rosenstock J, Bajaj HS, Janež A, et al. Once-weekly insulin for type 2 diabetes without previous insulin treatment. $N$ Engl J Med 2020;383:2107-16.

47 Home PD. The pharmacokinetics and pharmacodynamics of rapidacting insulin analogues and their clinical consequences. Diabetes Obes Metab 2012;14:780-8.

48 Thalange N, Bereket A, Larsen J, et al. Insulin analogues in children with type 1 diabetes: a 52-week randomized clinical trial. Diabet Med 2013;30:216-25.

49 Hermansen K, Fontaine P, Kukolja KK, et al. Insulin analogues (insulin detemir and insulin aspart) versus traditional human insulins (NPH insulin and regular human insulin) in basal-bolus therapy for patients with type 1 diabetes. Diabetologia 2004;47:622-9.

50 Kesavadev J, Saboo B, Krishna MB, et al. Evolution of insulin delivery devices: from syringes, pens, and pumps to diy artificial pancreas. Diabetes Ther 2020;11:1251-69.

51 Paton JS, Wilson M, Ireland JT, et al. Convenient pocket insulin syringe. Lancet 1981;1:189-90.

52 Roe MJ, Ignaut D, Miyakawa T, et al. Dose accuracy testing of the humalog/ humulin insulin pen device. Diabetes Technol Ther 2001;3:623-9.

53 Korytkowski M, Bell D, Jacobsen C, et al. A multicenter, randomized, open-label, comparative, two-period crossover trial of preference, efficacy, and safety profiles of a prefilled, disposable pen and conventional vial/syringe for insulin injection in patients with type 1 or 2 diabetes mellitus. Clin Ther 2003;25:2836-48.
54 Asakura T, Seino H, Nakano R, et al. A comparison of the handling and accuracy of syringe and vial versus prefilled insulin pen (FlexPen). Diabetes Technol Ther 2009;11:657-61.

55 Berget C, Messer LH, Forlenza GP. A clinical overview of insulin pump therapy for the management of diabetes: past, present, and future of intensive therapy. Diabetes Spectr 2019;32:194-204.

56 Rubin RR, Peyrot M, Chen X, et al. Patient-reported outcomes from a 16-week open-label, multicenter study of insulin pump therapy in patients with type 2 diabetes mellitus. Diabetes Technol Ther 2010;12:901-6.

57 Polonsky WH, Hessler D, Layne JE, et al. Impact of the omnipod ${ }^{\circledR}$ insulin management system on quality of life: a survey of current users. Diabetes Technol Ther 2016;18:664-70.

58 Charleer S, Mathieu C, Nobels F, et al. Effect of continuous glucose monitoring on glycemic control, acute admissions, and quality of life: a real-world study. J Clin Endocrinol Metab 2018;103:1224-32.

59 Ewen M, Joosse H-J, Beran D, et al. Insulin prices, availability and affordability in 13 low-income and middle-income countries. BMJ Glob Health 2019;4:e001410.

60 Chan JCN, Lim L-L, Wareham NJ, et al. The lancet commission on diabetes: using data to transform diabetes care and patient lives. Lancet 2021;396:2019-82.

61 Litchman ML, Oser TK, Wawrzynski SE, et al. The underground exchange of diabetes medications and supplies: donating, trading, and borrowing, oh my! J Diabetes Sci Technol 2020;14:1000-9.

62 Wang Z, Wang J, Kahkoska AR, et al. Developing insulin delivery devices with glucose responsiveness. Trends Pharmacol Sci 2021;42:31-44.

63 Thermalin pipeline. Available: http://thermalin.com/\#ourscience [Accessed Mar 2021].

64 Halberg IB, Lyby K, Wassermann K, et al. Efficacy and safety of oral basal insulin versus subcutaneous insulin glargine in type 2 diabetes: a randomised, double-blind, phase 2 trial. Lancet Diabetes Endocrinol 2019;7:179-88.

65 Tan SY, Mei Wong JL, Sim YJ, et al. Type 1 and 2 diabetes mellitus: a review on current treatment approach and gene therapy as potential intervention. Diabetes Metab Syndr 2019;13:364-72.

66 Regenerative medicine. Department of health and human services, 2006. Available: https://stemcells.nih.gov/info/Regenerative_ Medicine.htm [Accessed Feb 2021]. 